\title{
BANNED ORGANOCHLORINE PESTICIDES RESIDUE STILL OCCUR IN CATTLE MILK FROM KHARTOUM STATE
}

\author{
Sara A.M. ${ }^{1} \bowtie$, Afaf I.A. ${ }^{2}$, Sahar M.A. ${ }^{1}$, Abubakar A.S. ${ }^{3}$, Abdelbagi A.O. ${ }^{4}$, Abdalla A.M. ${ }^{4}$ \\ ${ }^{1}$ Department of Biochemistry, Nutrition, Pharmacology and Toxicology, Central Veterinary Research \\ Laboratory, Sudan. \\ ${ }^{2}$ College of Veterinary Medicine, University of Khartoum, Sudan. \\ ${ }^{3}$ Department of Entomology, Central Veterinary Research Laboratory, Sudan. \\ ${ }^{4}$ University of Khartoum College of agriculture, Sudan.
}

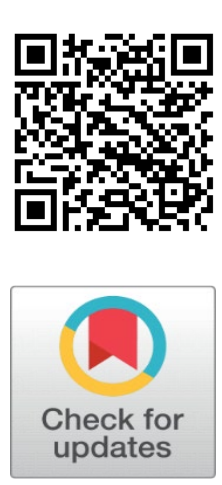

Received 17 November 2021

Accepted 4 December 2021

Published 31 December 2021

\section{CorrespondingAuthor}

Sara Ahmed Mohamed,

sarah_biochem@hotmail.com

DOI

10.29121/granthaalayah.v9.i12.2021 .4408

Funding: This research received no specific grant from any funding agency in the public, commercial, or not-for-profit sectors.

Copyright: (C) 2021 The Author(s). This is an open access article distributed under the terms of the Creative Commons Attribution License, which permits unrestricted use, distribution, and reproduction in any medium, provided the original author and source are credited.

\section{ABSTRACT}

Background: Pesticides application for controlling pests, has been a matter of debate for long time. In order to guarantee sustainable human health, this application should be monitored continuously.

Materials and Methods: 65 samples of cattle milk were collected from different Khartoum state's municipals; to assess the OCP residue, samples were extracted with petroleum ether and cleaned up using silica gel, then read out by GC equipped with FID. Result: Two pesticides belong to OCP were detected, Endosulfan (69.8\%) and Heptachlor (92\%); the detected concentration of the second one was outstanding, as all positive samples were above the MRL.

Keywords: Organochlorine, GC, Heptachlor, Endosulfan, Milk

Abbreviations: $\mathrm{OCP}=$ organochlorine pesticides, $\mathrm{GC}=\mathrm{Gas}$ chromatography, FID=Flame ionization detector.

\section{INTRODUCTION}

Balance between the economic advantageous usage of pesticides, which guarantee covering the raising demand of food especially in developing countries and avoidance of their harmful effect on environment and human health; represents a real challenge to agricultural sector and to the countries entirely. Pesticides are used to protect crops against undesirable organisms. A pesticide, may consist of one constituent, or mixture of substances. Pesticides can be categorized into different classes, there are synthetic and biological pesticides. Also, the pesticide may possess broad spectrum action or narrow spectrum one; that selectively kill small group of species by obstructing vibrant processes in the target organism Al-Zahraa et al. (2016). Depending on their environmental and human health threatening influence, pesticides could be categorized for example; Formothion, Simazine and dichloro diphenyl trichloroethan (DDT), are belong to the extremely hazardous pesticides category Jehad (2020). Consequently, organizations in charge and countries, prohibited their registration, aiming to ban their usage in agricultural sector. Dairy products such as milk and yoghurt are essential source of protein, carbohydrates, fats and various important minerals needed for heathy growth of children Abou-Dounia et al. (2010). Commitment with pesticides usage regulations provides safe dairy products. The 
chemical and physical properties of many organochlorines, regarding their separating and pressure under the ambient temperature, low solubility in water gave them the stability and capability to become highly persist compounds under furthermost environmental situations. The bioaccumulation of organochlorine pesticides through the food chain, is originated from their tendency to be soluble in fats Nida et al. (2009). Field applications of pesticides, represent the direct rout in which OCP move into the environmental system. Clearance of polluted wastes, the ability of some volatile OCP to adhere to soil or air and the adsorption of OCP by the aquatic system and accumulation in fish and other marine life components are all indirect routs to spread into the ecological systems.

Availability of data about the types and quantities of pesticides in the environment and/or food could be acquired by milk pursuing. The abstracted evidence is valuable for expecting health issues associated to milk consumption, which contribute in pesticides ingestion into human's bodies throughout the different stages of their lives. Subsequently the prediction of environmental chemicals in milk and milk products, gets a massive scientific devotion and concern Sara et al. (2019). Therefore, this study targeted the exploration the presence of different members of organochlorine class, intensively applied in the agricultural sector in Khartoum state. Moreover, to display the situation of those pesticides' residue in milk samples.

\section{MATERIALS AND METHOD 2.1. STUDY AREA}

The Khartoum state with its three big towns (Khartoum, Khartoum Bahri and Omdurman), was the targeted area of this surveillance. Probability sampling method was followed, to insure optimum coverage of all areas.

\subsection{CHEMICALS}

All chemical used for this analysis were GC grade.

\subsection{STANDARDS}

pesticides standards were obtained from department of crops protection, college of Agriculture-University of Khartoum.

\subsection{SAMPLE COLLECTION}

A total of 63 milk samples were collected in sterilized $500 \mathrm{ml}$ containers, and immediately transferred to refrigerator to avoid any other environmental contaminations.

\begin{tabular}{ll}
\hline \multicolumn{2}{l}{ GC analysis condition: } \\
\hline Detector & FID \\
\hline Column & DB-5, Film thickness $0.25 \mathrm{um}$, Inner diameter $0.25 \mathrm{~mm}$, Column length $30 \mathrm{~m}$. \\
\hline Carrier gas & N2/Air \\
\hline Injection mode & Spilt \\
\hline
\end{tabular}




\subsection{SAMPLE PREPARATION}

\subsubsection{EXTRACTION}

A $(500 \mathrm{~mL})$ of milk sample was transferred into a reparatory funnel. (50 ml) of Petroleum ether was added and shaken well. Another portion of petroleum ether (200 $\mathrm{mL}$ ) was added and Sodium Chloride $(\mathrm{NaCl})$ was also added to boost separation. The sample was rotated and allowed to settle for overnight. The lower layer discarded. Petroleum ether $(200 \mathrm{~mL})$ was added to the top layer, and $\mathrm{NaCl}(2$ g) was also added to boost separation. The lower layer was drained out. This process was repeated three times and the top layer was collected in a $250 \mathrm{~mL}$ volumetric flask. The petroleum ether was concentrated to $1 \mathrm{ml}$ using rotary evaporator $\mathrm{AOAC}$ (1995)

\subsubsection{PARTITIONING}

Partitioning of the extracted milk samples was carried out according to Leon et al. (1990). To the petroleum ether concentrated sample, a (10 mL) Acetonitrile was added and again concentrated to $5 \mathrm{ml}$. ( $3 \mathrm{~mL}$ ) petroleum ether was added and the mixture was mixed well and allocated in the freezer for two hours, the petroleum ether was dismissed to remain with acetonitrile to remove the fats. The extract was further concentrated to 3 milks Enid (2013).

\subsubsection{CLEANUP}

The extracts, about $(5 \mathrm{ml})$ were transferred to silica gel cartridge (pre-washed with petroleum either and acetonitrile (75: 25 by volume; $10 \mathrm{ml}$ ) ) and eluted with petroleum either and acetonitrile (75:25 by volume; $25 \mathrm{ml})$ at rate $510 \mathrm{ml} / \mathrm{min}$. The eluent was collected and evaporated to dryness with a rotary vacuum evaporator at $60 \mathrm{oC}$. The residue was dissolved in $3 \mathrm{ml}$ acetonitrile, and filtered through a membrane filter $(0.45 \mathrm{am})$ and analyzed by gas chromatography.

\section{Statistical analysis}

The data were analyzed by using Statistics-10 program designed for Windows. Differences between obtained values were carried out by analysis of variance (ANOVA) the LCD test was used for determining the significance level of at least $p<0.05$.

\section{RESULTS AND DISCUSSION}

Endosulfan belongs to organochlorine pesticides class, sub class of cyclodeine. There two isomers of endosulfan; alpha and beta one. Central nervous system, liver and kidney are the main tissues influenced by endosulfan exposure Jaiswal et al. (2005). Application of endosulfan in agricultural sector, resulted in infants delivered with mental impairments and limbs defects, moreover, endosulfan has carcinogenic and mutagenic effects Pradeep et al. (2009).

About $70 \%$ of analyzed samples were found positive for enosulfan residue ( 44 sample), with mean concentration $0.006 \mathrm{ppm}$. Positive samples distributed between different localities as follows; Khartoum Bahri locality, recorded 16 positive samples out of 25 (64\%), all positive samples were below the maximum residue limit stablished by codex (2006). The city of Khartoum, recorded 13 positive samples out of $19(68 \%)$, five of them exceeded the MRL, that represented (38\%). Omdurman 
locality showed, 15 positives out of 19 positive samples (78\%), with five samples above the MRL (33.3\%). Comparing mean concentrations of endosulfan residue obtained from various state's localities revealed, significant ( $p<0.001$ ) low concentration in samples delivered from Bahri municipal compared to those collected from Khartoum and Omdurman. Concurrently, mean concentration values of endosulfan residue was not significantly different at $(p<0.005)$ between samples obtained from Khartoum and Omdurman municipals.

The current study result regarding the occurrence and concentration of endosulfan residue, is similar to that obtained by Nida et al. (2009) and co-workers, who reported presence of OCP residue in $20.6 \%$ of dairy products collected from different regions of Jordan. Though the endosulfan was detected in only one sample, but the concentration was above the MRL. Organochlorine and organophosphorus pesticides residue in fodder and milk samples along Musi River-India, was investigated by Korrapati et al. (2015) although the OCP residue was detected in milk samples but the level was quite under the MRL.

Endosulfan residue was also detected in cattle milk samples assembled from various areas of Faisal Abad-Pakistan by Faqir et al. (2012), they analyzed samples using HPLC, after samples extracted according to solid phase micro extraction method, the obtained results revealed endosulfan and cypermethrin in concentrations exceeded the MRL.

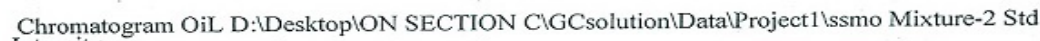

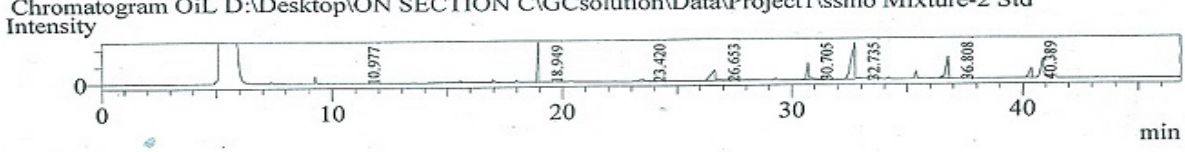

\begin{tabular}{|r|r|r|r|r|r|r|l|}
\hline \multicolumn{1}{|c|}{ Peak\# } & Ret. Time & \multicolumn{1}{|c|}{ Area } & \multicolumn{1}{|c|}{ Height } & \multicolumn{1}{|c|}{ Conc. } & Units & Mark & \multicolumn{1}{|c|}{ Name } \\
\hline 1 & 10.977 & 51 & 44 & 0.000 & & & \\
\hline 2 & 18.949 & 1709523 & 469147 & 283.507 & $\mathrm{mg} / \mathrm{ml}$ & & Diazinone \\
\hline 3 & 23.420 & 317541 & 19205 & 1010.108 & $\mathrm{mg} / \mathrm{ml}$ & & Omethoate+DDA \\
\hline 4 & 26.653 & 1762631 & 122397 & 2475.652 & $\mathrm{mg} / \mathrm{ml}$ & & Dimethoate \\
\hline 5 & 30.705 & 1359276 & 191846 & 141.671 & $\mathrm{mg} / \mathrm{ml}$ & & Heptachlor \\
\hline 6 & 32.735 & 4535127 & 425675 & 418.383 & $\mathrm{mg} / \mathrm{ml}$ & & Chlorpyrifos \\
\hline 7 & 36.808 & 2095083 & 254026 & 259.208 & $\mathrm{mg} / \mathrm{ml}$ & & Endosulfan alpha \\
\hline 8 & 40.389 & 828486 & 108621 & 126.393 & $\mathrm{mg} / \mathrm{ml}$ & & Endosulfan Beta \\
\hline Total & & 12607718 & 1590961 & & & & \\
\hline
\end{tabular}

Figure 1 Elution pattern of standards mixture

Heptachlor is classified under chlorinated dicyclopentadeine insecticides. It is white crystalline synthetic compound with camphor-like odor, used in the past to kill insects in homes and crops. Heptachlor is capable to stick to the soil strongly, evaporate into the air, but it's capability to dissolve in water is poor Kielhorn et al. (2006). Most common rout of heptachlor exposure is when we ingest food polluted with this chemical, contaminated food may include fish, dairy products and meat. In halation of air polluted with heptachlor, allow this chemical to enter the blood stream and the lung mutually, and once heptachlor is there, studies in animals reported evidence of deterioration in central nervous system Costa (2019) and immune system, additionally low weight newborn animal's cases were observed as well syracuse research corporation (2007). Though the usage of heptachlor has been banned or restricted since eighteenth of past century, still its residue detected in food from different origin Figure 2. 


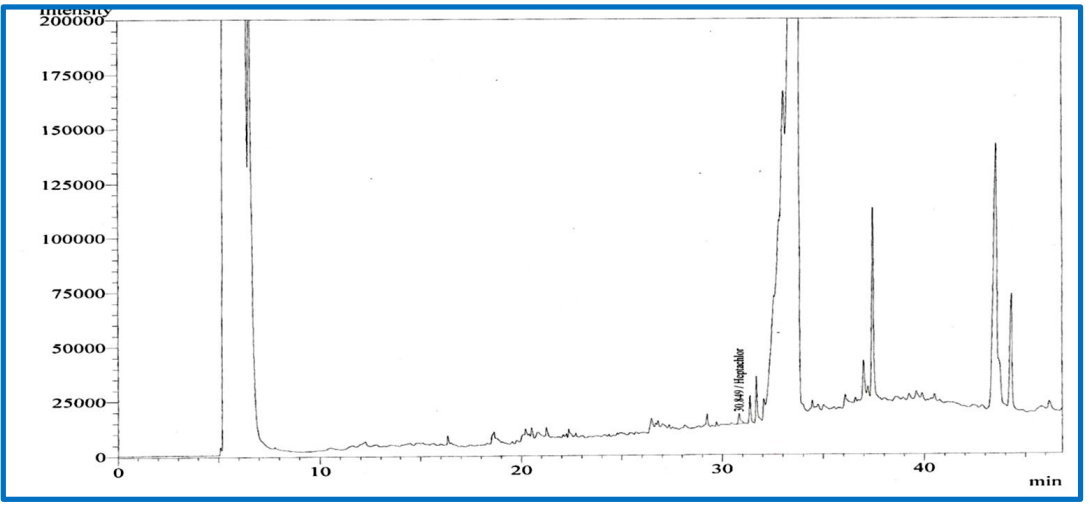

Figure 2 Elution pattern of Heptachlor

\begin{tabular}{|lccc}
\hline \multicolumn{4}{l}{ Table 1 Some info about the detected pesticides } \\
\hline Pesticide Name & Molecular Formula & Molecular Weight & Codex (MRL) \\
\hline Heptachlor & $\mathrm{C} 10 \mathrm{H} 5 \mathrm{Cl} 7$ & $373.32 \mathrm{~g} / \mathrm{mol}$ & $0.006 \mathrm{ppm}$ \\
\hline Endosulfan & $\mathrm{C} 9 \mathrm{H} 6 \mathrm{Cl} 603 \mathrm{~S}$ & $406.93 \mathrm{~g} / \mathrm{mol}$ & $0.01 \mathrm{ppm}$ \\
\hline
\end{tabular}

Heptachlor positive samples represented 92\% (58), of total collected samples with mean concentration value $0.02 \mathrm{ppm}$. Most remarkable thing about heptachlor result is that, all positive samples were above Codex MRL (0.006 ppm). Twenty-five samples were gathered from Bahri locality, 20 samples were positive for heptachlor residue $(80 \%)$, with mean value $(0.013 \mathrm{ppm})$. Municipal of Khartoum and Omdurman reported $100 \%$ positive samples. Statistically, no substantial variance between detected value was observed. Jehad (2020) reported positive heptachlor residue in milk samples collected from Amman-Jordan farms, with concentration exceeded the tolerant level. Furthermore, Alawi and Al-Hawadi (2003) reported sheep milk samples found to be heptachlor positive with a mean concentration of $0.5 \mathrm{ppm}$, which is above the permissible limit.

The behavior of the pesticide and its physical and chemical characteristics, make prediction of a certain pesticide fate easier. Stability of organochlorine pesticides, and resist to dissociate in environment, strong tendency to stick to soil particles for long time, exhibiting volatilization property and capability to accumulate in eco and biological systems provides numerous ways to detect residue in different types of foods from different origin in food chain.

Table 2 Minimum, maximum and mean of detected concentrations in milk samples

\begin{tabular}{ccccccc}
\hline Pesticide & Min & Max & Mean \pm SE & \multicolumn{2}{c}{ MRL } & \multicolumn{2}{c}{ Incidence (+) } \\
& ppm & ppm & & ppm & No & \% \\
\hline Heptachlor & 0.011 & 0.024 & $0.022 \pm 0.0059$ & 0.006 & 58 & 92 \\
\hline Endosulfan & 0.0003 & 0.024 & $0.0065 \pm 0.0017$ & 0.01 & 44 & 69.8 \\
\hline
\end{tabular}

According to the Codex Aliment Arius, residual pesticides exceeded MRL (mg/kg on fat basis). 


\section{CONCLUSION}

The argument about usage of pesticides, should be settled in favor of human health, and environmental safety. To achieve these two principal point, bearing in mind the benefits, and the real need of pesticides application- the laws govern the whole process related to pesticides usage should be activated and followed firmly.

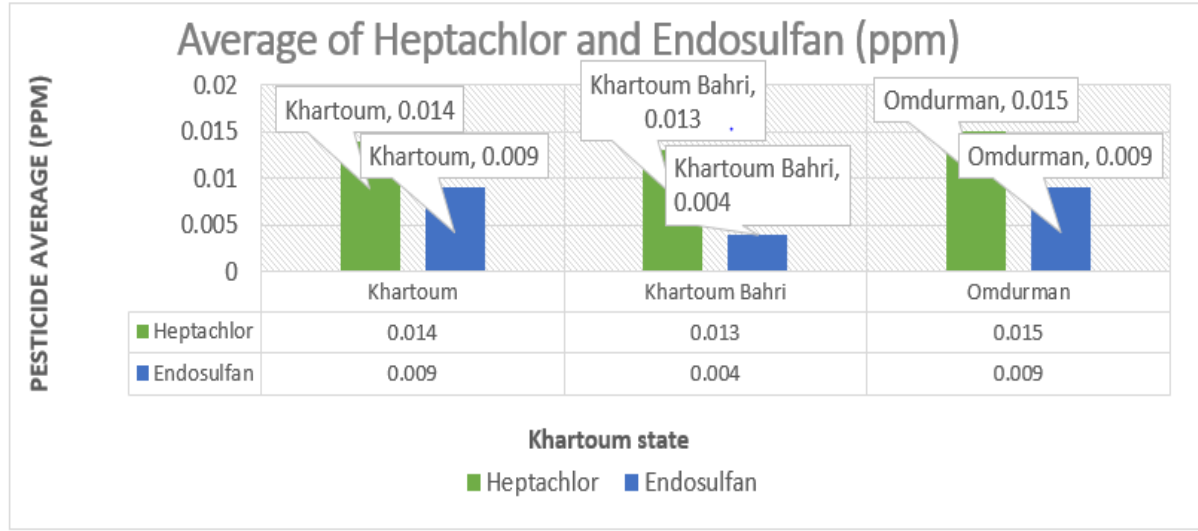

Figure 3 Average of detected pesticides in milk samples

\section{REFERENCES}

A.O.A.C. (1995). Official methods of the association Official Analytical Chemists. Washington. D.C.

Abou-Dounia MA, Abou-Arab AAK, El-Senaity MH, Abd-Rabou NS. (2010). Chemical composition of raw milk and the Accumulation of pesticide residues in milk products. Global veterinaria 4 (1) : 6-14. Retrieved from http://www.idosi.org/gv/gv4(1)10/2.pdf

Al-Zahraa MD, Soumia MD and Fathy EE. (2016). Analysis of Organochlorine and Organophosphorus Pesticide Residues in Dairy Products and Baby Foods from Egyptian Markets. Journal of Environmental \& Analytical Toxicology, 6(6). Retrieved from DOI : 10.4172/261-0525.1000412.

Alawi, M.A.; Al-Hawadi, J.S. (2003). Organochlorine pesticides in sheep milk and fodder in Jordan. J. Food Agric. Environ.3, 226-228.

Codex. (2006). Maximum residue limits for pesticide residues in food.

Costa, L.G. (2019). Central nervous system toxicity biomarkers. In Biomarkers in Toxicology; Elsevier: Amsterdam, The Netherlands,173-185. Retrieved from https://doi.org/10.1016/B978-0-12-814655-2.00010-4

Enid Turyahikayo. (2013). Assessing the levels of pesticide residues in livestock products and water around lake MBURO National Park, south western UGANDA. A dissertation submitted to Makerere University, College of agriculture and environmental sciences. Retrieved from http://hdl.handle.net/10570/3369

Faqir Muhammad, Ijaz Javed, Masood Akhtar, Zia-ur-Rahman, Mian Muhammad Awais, Muhammad Kashif Saleemi and Muhammad Irfan Anwar. (2012). Quantitative Structure activity relationship and risk analysis of some pesticides in the cattle milk. Pak Vet J, 32(4): 589-592.

Jaiswal, A., V. Kumar Parihar and M. Sudheer Kumar. (2005). 5-aminosalicylic acid reverses endosulfan induced testicular toxicity in male rats. Mutat. Res.- 


\section{Genet. Toxicol. $\quad$ E. $\quad$ M., $\quad$ 585(1-2): 50-59. Retrieved from https://doi.org/10.1016/j.mrgentox.2005.04.010}

Jehad S. Al-Hawadi. (2020). Banned Organochlorine Pesticides Still in Our Food: The Presence of Organochlorine Pesticide Residues in Milk, Meat, Liver, and Kidney in Jordan Cattle. Systematic Reviews in Pharmacy,11 (11). Retrieved from https://www.sysrevpharm.org/articles/banned-organochlorinepesticides-still-in-our-food-the-presence-of-organochlorine-pesticideresidues-in-milk-meat-liver-.pdf

Kielhorn, J.; Schmidt, S.; Mangelsdorf, I. (2006). Heptachlor; World Health Organization: Geneva, Switzerland.

Korrapati Kotinagu and Nelapati Krishnaiah. (2015). Organochlorine and organophosphorus pesticide residues in fodder and milk samples along Musi river belt, India. Veterinary World; 8:545-550. Retrieved from https://doi.org/10.14202/vetworld.2015.545-550

Leon, D.S., M.M. Bernardett, W.H. Newsome and A.P. Gail. (1990). Association of Official Analytical Chemistry; pesticide and industrial chemical residues, 274-291.

Nida' M. Salem, Rafat Ahmad, Hussein Estaitieh. (2009). Organochlorine pesticide residues in dairy products in Jordan. Chemosphere 77:673-678. Retrieved from https://doi.org/10.1016/j.chemosphere.2009.07.045

Pradeep Kumar S.P Singh, D. Madhukar and A.M. Kotresh. (2009). Determination of endosulfan residue in buffalo meat using high performance liquid chromatography, Buffalo Bulletin, 28(4).

Sara A. M., Afaf. A., Sahar M. A., Abubakar A. S., Abdelbagi A. O., Abdalla A. M. (2019). Organophosphorus pesticides residue in cattle milk from Khartoum state. Scientific Research Journal (SCIRJ), 7 (2). Retrieved from https://doi.org/10.31364/SCIRJ/v7.i1.2019.P0119603

yracuse research corporation. (2007). Toxicological profile for heptachlor and heptachlor epoxide. Prepared for US department of health and human services 